\title{
NASA's Radioisotope Power Systems Planning and Potential Future Systems Overview
}

\author{
June F. Zakrajsek \\ NASA Glenn Research Center \\ 21000 Brookpark Road \\ Cleveland, $\mathrm{OH} 44135$ \\ 216-977-7470 \\ june.f.zakrajsek@nasa.gov \\ Stephen G. Johnson \\ Idaho National Laboratory \\ 2525 Freemont Avenue \\ Idaho Falls, ID 83415 \\ 208-533-7496 \\ stephen.johnson@inl.gov
}

\author{
Dirk Cairns-Gallimore \\ U. S. Department of Energy \\ 19901 Germantown Road \\ Germantown, MD 20874 \\ 301-903-3332 \\ dirk.cairns-gallimore@nuclear.energy.gov \\ Louis Qualls \\ Oak Ridge National Laboratory \\ 1 Bethel Valley Road \\ Oak Ridge, TN 37831 \\ 865-574-0259 \\ quallsal@ornl.org
}

\section{INTRODUCTION}

\begin{abstract}
The goal of NASA's Radioisotope Power Systems (RPS) Program is to make RPS ready and available to support the exploration of the solar system in environments where the use of conventional solar or chemical power generation is impractical or impossible to meet the needs of the missions. To meet this goal, the RPS Program, working closely with the Department of Energy, performs mission and system studies (such as the recently released Nuclear Power Assessment Study), assesses the readiness of promising technologies to infuse in future generators, assesses the sustainment of key RPS capabilities and knowledge, forecasts and tracks the Program's budgetary needs, and disseminates current information about RPS to the community of potential users. This process has been refined and used to determine the current content of the RPS Program's portfolio. This portfolio currently includes an effort to mature advanced thermoelectric technology for possible integration into an enhanced Multi-Mission Radioisotope Generator (eMMRTG), sustainment and production of the currently deployed MMRTG, and technology investments that could lead to a future Stirling Radioisotope Generator (SRG). This paper describes the program planning processes that have been used, the currently available MMRTG, and one of the potential future systems, the eMMRTG.
\end{abstract}

\section{TABLE OF CONTENTS}

1. INTRODUCTION 1

2. Program PlanNing AND ASSESSMENT.............. 2

3. RTG INTEGRATION .......................................... 2

4. RPS SUSTAINMENT ................................................... 3

5. TeChNology Maturation Process................ 4

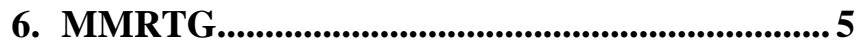

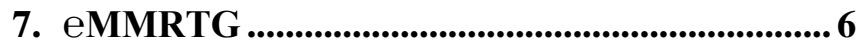

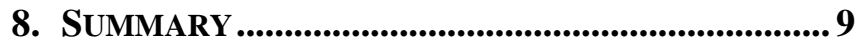

REFERENCES....................................................................... 9

BIOGRAPHY ....................................................... 10
The RPS Program, in partnership with the Department of Energy Office of Space and Defense Power Systems, is responsible for acquisition and development of thermal energy conversion technologies and related power system component technologies, as well as the acquisition of flight radioisotope power systems and insight into the needs of the user community. An important NASA objective is maintaining the capability to sustain existing RPS and acquire potentially new future systems through strategic investment in unique competencies.

RPS have been highly successful supporting United States space exploration, having been used on 27 space missions to date. The National Aeronautics and Space Administration (NASA), in partnership with the Department of Energy (DOE), has deployed RPS on extraordinary missions to the Moon, Mars, and the outer planets. RPS systems have had the same technological heritage used originally in 1961 and have reliably served NASA's exploration needs. RPS will continue to be essential for power generation on space science missions where the use of other means of energy conversion, such as solar arrays, is impractical because of diminished intensity moving farther from the sun or shadowing of the sun's light.

Thermoelectric conversion technology integrated with radioisotope heat sources form Radioisotope Thermoelectric Generators (RTGs). Seven basic RTG configurations have been flown in space by the United States. They originated from the Systems Nuclear Auxiliary Power (SNAP) Program (SNAP-3, SNAP-9, SNAP-19, SNAP-27 were flown), and matured into newer configurations to support different mission requirements. The Multi-Hundred Watt RTG (MHW-RTG) and General Purpose Heat Source RTG (GPHS-RTG) designs were products of further system maturation. The seventh and current RTG configuration is the Multi-Mission RTG (MMRTG), which is currently 
providing the power to explore the surface of Mars on the Mars Curiosity rover.

While all configurations of radioisotope power systems flown to date have been based on thermoelectric energy conversion, investments in other energy conversion research have also been made. Dynamic power conversion methods have been studied for application in radioisotope power systems and show the promise of efficiency gains, but have not yet been flown. The RPS Program has plans to develop dynamic power technology, specifically Stirling cycle convertors, that could lead to a Stirling RPS.

The RPS Program, acting on behalf of the Science Mission Directorate (SMD) performs the following functions:

- Provides strategic leadership and prepares for radioisotope power systems use by the planetary science community;

- Acquires flight hardware, through DOE, and supports flight mission development, launch, and operations (as needed);

- Maintains a robust technology development portfolio;

- Works to reduces National Environmental Policy Act (NEPA) and launch safety approval schedule risk;

- Maximizes utilization of the available Pu-238 supply in the development of RPS for science missions;

- Provides insight to DOE implementation of RPS-related production infrastructure operations;

- Provides insight to DOE implementation of the Plutonium-238 Supply Project.

This paper describes the planning necessary to prioritize the RPS Program investments and provides a summary of current RPS investments; the MMRTG, and a potential upgrade to that system which utilizes advanced thermoelectrics, the enhanced MMRTG (eMMRTG).

\section{Program Planning and Assessment}

Program Planning and Assessment (PP\&A) ensures that the flow of technology development is responsive to the evolving needs of the science community and stakeholders and supports the implementation strategy of the RPS Program to meet the Level I requirements and stakeholder expectations. PP\&A includes the following major functions: mission studies, systems analysis and studies, program assessment, stakeholder engagement and integration, sustainability assessment, acquisitions, strategy development, road mapping and systems engineering and integration. These functions are organized into Mission Analysis, RTG Integration, and SRG Integration areas. The RTG Integration and Stirling Integration element consists of system analysis, modeling, testing, system engineering functions, and flight project support. All of these areas function together to carry out the scope of the PP\&A element. Thus, the PP\&A element is crosscutting and interacts with all aspects of the RPS Program and its projects Mission and systems analyses provide the engineering foundation the program uses to prioritize current and future RPS investments. These functions are implemented by support from NASA Goddard Space Flight Center (GSFC) and Glenn Research Center (GRC) and by contract support from the Johns Hopkins University Applied Physics Laboratory (APL), and the Jet Propulsion Laboratory (JPL). Mission and systems analyses are used to inform the RPS Program Manager and RPS Program Executive concerning program investment options that would best serve all stakeholders. Mission analyses allow the Program to forecast and understand which mission scenarios could be enabled by a RPS and the mission science benefits that would support NASA 2014 Strategic Objective 1.5, "Ascertain the content, origin, and evolution of the solar system and the potential for life elsewhere". Mission analysis identifies the top-level capabilities needed in a RPS as well as potential impacts the RPS would have on a spacecraft. This information is used to define which system-level analyses are required. System analyses are used to understand system level requirements and parameters and compare those to current capability.

A technology-specific systems analysis is typically performed for both thermoelectrics and Stirling-based technologies. This process is used to inform the need for RPS technology that might lead to new RPS capabilities to enable missions with requirements beyond current performance parameters. Mission designs are sometimes conducted for the purpose of broadening the potential applicability of RPS applications to the SMD in general. The Nuclear Power Assessment Study (NPAS) is an example of this process. [1] PP\&A has responsibility for providing integration of these analyses, both mission and systems, for RPS across all organizations conducting program related analyses.

To determine the applicability of power systems for NASA missions and evaluate the associated science or exploration returns, the Mission Analysis (MA) team develops Design Reference Missions (DRMs) using both notional and anticipated RPS capabilities. The MA team specifically investigates the impacts of the power systems in the areas of mission development, integration, operation, reliability, lifecycle cost, risk, and mission safety. The Mission Analysis team also generates Rough Order of Magnitude (ROM) mission costs for evaluated missions.

\section{RTG INTEGRATION}

RTG Integration (RI) provides management and technical support in three broad categories: Flight Project Support, Radioisotope Power Systems, and Modeling and Testing. This support is coordinated with NASA and the DOE. Flight Project Support aids NASA's space missions from concept through launch. The support is primarily for RTGs, but can also provide insight on the use of Radioisotope Heater Units 
(RHUs). As examples, support is being provided to Mars 2020 and to NASA's New Frontier (NF) Program in the form of planning and budget estimating.

Should NASA choose to provide MMRTGs for a NF mission, RTG Integration support would transition to the more formal interaction typically provided to missions. Such support spans engineering consulting, lessons learned, budgeting, test planning, monitoring, RTG information dissemination, both formal and peer reviews, programmatic reporting, among others. Unique Memorandums of Understanding (MOU) are written to document the precise level of support.

Flight Project Support is augmented by bottoms-up engineering as well. RTG Integration's Modeling and Testing (M\&T) area funds tests needed to improve RTG models. MMRTGs, such as the one powering the Curiosity rover, have a design lifetime of 17 years, yet there was no means to test the generator or its assemblies for 17 years before it was launched. Power predictions were made before launch but were largely based upon data from previous generator designs such as those flown on the Pioneer and Viking missions. As a consequence, the life performance predictions included uncertainty. JPL is testing coupons, parts, and assemblies to better understand the long-term performance of the MMRTG and refine the physics based models for missions using MMRTGs. These tests will continue until at least Fiscal Year (FY) 2019 when the MMRTG on Curiosity will have been operating continuously for 11 years.

M\&T can also perform tests of anomalies or uncertain events. For example, a spacecraft can include pyrotechnic devices to perform in-flight functions. Activation of these devices is typically immediately followed by a high-frequency shock that propagates through the chassis of a spacecraft. During one qualification-level pyrotechnic test, the MMRTG was subjected to a severe over-test and a slight drop in output power was cataloged. The power recovered within $\sim 15-20$ minutes, but the root cause was not identified.

It is difficult to investigate unexpected events in RTGs such as the MMRTG since it is hermetically sealed and welded shut. Opening an MMRTG is a destructive act involving an expensive asset and the act of taking apart a unit could destroy the evidence that is sought. Rather than destructive evaluation, M\&T is executing tests to shorten the list of potential root causes for the power reduction and recovery observed on the MMRTG. Thermoelectric couples and modules of couples are being subjected in the laboratory to a variety of dynamic loads, including actual pyrotechnicallyinduced shocks. [2] This investigation is on-going in support for future MMRTG use and is also providing new tools to investigate similar phenomenon in RTGs in general.

The RTG group within RI provides conceptualization and planning for future RPS and tracks the performance of previously deployed RTGs. The MMRTG was conceived circa 2003. Since then, technological advances in thermoelectric materials have been made that suggest an enhanced version of the MMRTG should be feasible. NASA is funding development and evaluation of a "drop-in" replacement technology that based on these new materials that could boost power at both the beginning of a mission (BOM) and, most significantly, at the end of the generators design life (EODL) compared to that of the current MMRTG. These new thermoelectric couples for a potential eMMRTG are being developed by industry, based upon technology developed at JPL. Preliminary engineering evaluation of this "enhanced" MMRTG is occurring in parallel. If these two endeavors are successful, NASA may elect to have the DOE develop these eMMRTGs for flight.

Other concepts have been studied by RI, including an RTG with segmented thermoelectric couples packaged in a readily scalable module design. Such a generator could potentially deliver $\sim 450 \mathrm{~W}$ with a mass of $\sim 50 \mathrm{~kg}$. This configuration could potentially be scaled down $\sim 90 \mathrm{~W}$ in a $20 \mathrm{~kg}$ system. Even smaller devices such as $15-20 \mathrm{~W}$ at $5 \mathrm{~V}$ in a $10 \mathrm{~kg}$ package have also been studied.

The above content description, although specific to RTG Integration, is similar for the SRG Integration area of PP\&A, except that the content is focused on Stirling systems and investments. [3]

\section{RPS SUSTAINMENT}

In order to support future missions, NASA and DOE must maintain the capability to produce RPS. The financial support for maintaining the capability to produce RPS is provided by NASA. This funding is independent of NASA's mission funding. Relevant areas of support include sustainment of skills, capabilities, and infrastructure; human knowledge bases; and facilities. The relative risk and sustainment factors of these categories are constantly evaluated. However, the trade is not "either/or" but rather a spectrum that requires optimization, and must consider costs and benefits.

To aid this process, NASA levied a requirement on the RPS Program stating that "The RPS Program shall sustain current and future RPS capabilities and the necessary support functions to provide for future missions as required." The objective of this requirement is to ensure that RPS expertise, capabilities, and infrastructure is supported between implementing missions as a means to maintain a repository of corporate knowledge and lessons learned. This top-level requirement is led by the RPS program, working with the DOE, to identify capabilities that must be maintained. The process has four steps: 1) Identify current critical and key RPS capabilities; 2) Identify RPS critical and key capabilities that can be supported by funded in-line work; 3) Identify risk of losing a RPS capability; 4) Develop sustainment recommendations. The RPS Program's definition of sustainability is "Long-term management of critical or key Government and Contractor competencies, skills, and facilities." In this context, "management" means to strategically and economically balance these critical assets 
across the RPS Program portfolio to meet the nation's space exploration needs, in both content and phasing.

Applying the capabilities assessment process, the following RPS Program key competencies and skills were identified for the MMRTG area: 1) Thermoelectric principles, materials, and couple development, modeling, testing, and production, and supporting laboratories; 2) Stirling principles, convertor development, modeling and testing, and supporting laboratories; and, 3) nuclear risk analysis, probabilistic risk assessment, accident scenario modeling and analysis, risk communications, radiological contingency planning, and compliance engineering and planning. For the thermoelectric conversion technology areas, sustainment-funding levels of $\sim 4$ million per year are currently baselined for NASA inhouse government capabilities and $\sim 3$ million per year for industry support. For nuclear launch approval capabilities, $\sim 2$ million per year is baselined for NASA in-house capabilities. Given the current, combined NASA budget for missions and the RPS Program, these levels of sustainment are funded by a combination of in-line mission costs, support to missions, or technology development work.

It is also important to sustain the DOE facilities used to integrate and fuel RPS. Previously, DOE funded maintenance of a set of capabilities (facilities, equipment, and core staff) to support the potential NASA mission use of RPS. The FY2014 Congressional appropriation shifted accountability for paying for all associated infrastructure to NASA via an addition of $\$ 50$ million per year to the PSD budget, consistent with the NASA FY2014 President's Budget Request [4]. NASA chartered a DOE RPS Infrastructure and $\mathrm{Pu}-238$ Production Zero Base Review in May 2013 to review the adequacy of the budgeted amounts.

The associated arrangements between agencies are documented in a tiered Interagency Agreement (IAA) that supplements the 1991 MOU [5]. The work sustains a base level of qualified staff and keeps key facilities in an operational mode, including any improvements; a base level of safety and technical analysis capabilities; nuclear materials and systems transportation and storage; and, procurement of hardware as needed to sustain a limited supply chain or to level production rates between missions. In addition, NASA is funding the DOE to sustain industry to produce fine weave pierced fabric (FWPF) for GPHS module bodies; to reestablish the capability to produce $\mathrm{Pu}-238$ domestically (the Plutonium Supply Project); and, to install a new replacement Hot Press and associated furnaces (at Los Alamos National Laboratory (LANL)) to support NASA mission needs.

\section{Technology Maturation Process}

The RPS Program, through the PP\&A process, assesses the need for new mission-driven technologies. These technologies are selected for their value in strategically supporting multiple future flight mission concepts. When gaps are identified, the program may elect to fund development and maturation of the technology to the point that it can be included as a capability to flight systems development efforts. The program also seeks to identify key new technologies through means such as the NASA Research Announcement entitled Research Opportunities in Space and Earth Sciences (ROSES) sponsored annually by the NASA SMD and Small Business Innovative Research (SBIR) awards. The development of new technologies is a key component of the RPS Program. The teaming of industry, academia, and government is encouraged to foster an environment conducive to technology development and utilization. The RPS Program technology projects manage their technology maturation as defined in NASA Procedural Requirements (NPR) 7120.8. The RPS Program has established two technology projects for managing the research and development of advanced radioisotope power conversion and supporting subsystem technologies.

The RPS Thermoelectric Technology Development Project (TTDP), managed by JPL for the program and the StirlingCycle Technology Development Project, managed by GRC for the program, are the Program's two core Research \& Technology (R\&T) Portfolio Projects. The projects support the RPS Program's strategic objectives of providing radioisotope power system capabilities for potential future NASA space science mission requirements and sustaining current and future RPS capabilities and the necessary support functions. The projects provide the overall management of technology advancement activities for RPS power conversion and relevant subsystems.

Each technology project develops technology ranging from Technology Readiness Level (TRL) 1 to TRL 6. The projects are structured to move technology from low-TRLs to midrange TRLs. When the projects have tasks to mature to a TRL of 5/6, a technology maturation plan and a set of requirements are developed working with the DOE.

These requirements can be used to initiate a DOE Flight systems development project. Based on lessons learned from other technology development efforts, it is clear that a combination of a strong NASA and DOE partnership along with industry participation is necessary for successful technology maturation. In addition, technology gates should be clearly established such that progress is objectively evaluated by external specialists in missions, systems, technology and project management before proceeding to the next phase. This approach helps ensures that flight system development does not begin before the technology, development plan and risks are properly understood. The nominal technology development process for the RPS Program is shown in Figure 1.

This process is being followed for the Skutterudite (SKD) Technology Maturation task under TTDP that could potentially lead to a decision to develop the eMMRTG, which just successfully completed its Gate 1 review. 


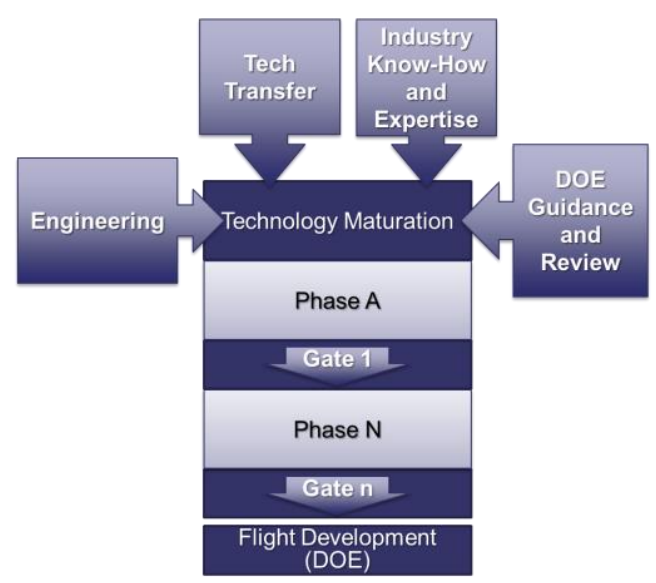

\section{MMRTG}

The MMRTG, shown in Figure 2, is the currently available RPS system. The MMRTG is powered by eight plutonium dioxide-fueled GPHS modules. The RTG produces electrical power as heat flows through the thermoelectric (TE) modules. Heat that is not converted to electricity is rejected to the environment by eight external radiation fins. The flow of heat creates a temperature gradient across the thermoelectric couple that produces a voltage via the Seebeck effect. This voltage is converted to power when a load, which completes the circuit, is placed across the thermoelectric string. The performance parameters for a MMRTG are listed in Table 1 .

Figure 1. Technology Maturation Model.

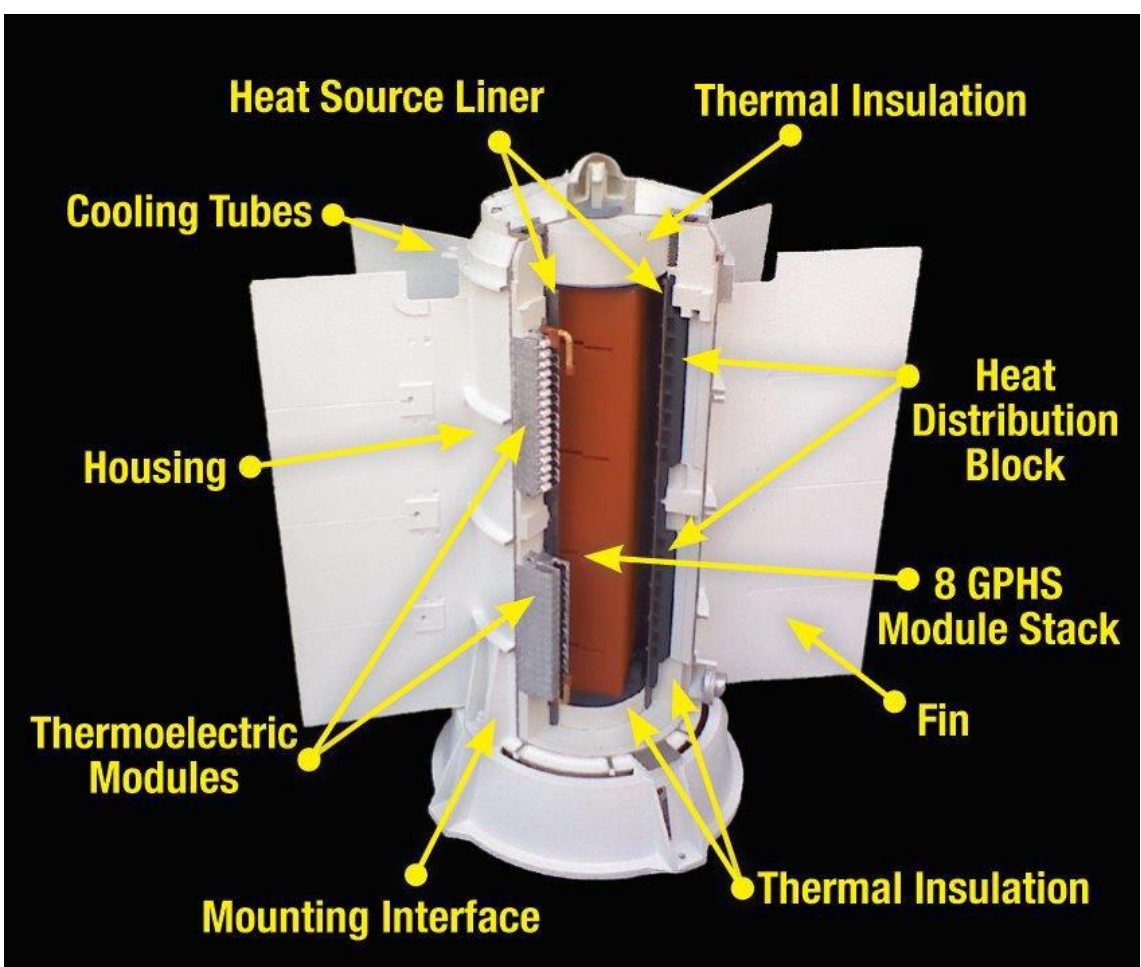

Figure 2. Cutaway view of the MMRTG showing eight GPHS modules, thermoelectric conversion modules and radiation fins. 
Table 1: Nominal performance parameters of the MMRTG

\begin{tabular}{|l|l|}
\hline \multicolumn{1}{|c|}{ Parameter } & \multicolumn{1}{c|}{ MMRTG } \\
\hline Power, electrical (BOM*) & $110 \mathrm{We}$ \\
\hline Power, thermal (BOM $\left.{ }^{*}\right)$ & $2,000 \mathrm{Wth}$ \\
\hline Design Lifetime & $17 \mathrm{yrs}(14 \mathrm{yrs}$ operational) \\
\hline Diameter, fin-tip to fin-tip & $64 \mathrm{~cm}(25 \mathrm{in})$ \\
\hline Height & $66 \mathrm{~cm}(26 \mathrm{in})$ \\
\hline Mass & $45 \mathrm{~kg}(94 \mathrm{lbs})$ \\
\hline Voltage Range & $23-36 \mathrm{~V} \mathrm{dc}$ \\
\hline Max Fin Root Temperature & $200 \mathrm{C}$ \\
\hline $\begin{array}{l}\text { Random Vibration Qual } \\
\text { Limit }\end{array}$ & $0.2 \mathrm{~g} 2 / \mathrm{Hz}$ \\
\hline $\begin{array}{l}\text { Pyrotechnic Shock Qual } \\
\text { Limit }\end{array}$ & $6,000 \mathrm{~g}$ \\
\hline
\end{tabular}

The MMRTG utilizes 16 thermoelectric (TE) modules, as shown in Figure 2, connected in electrical series to produce $\sim 120$ Watts of electricity at $\sim 28$ to $\sim 32$ Volts. These 16 modules are located inboard of the eight (8) aluminum heat rejection fins, with eight pairs of modules aligned axially. The modules are captured between an inner isolation liner and the aluminum housing. Modules contain spring-loaded cold side pistons that conduct heat from the cold junction of the couple into the module bar and then into the housing. The spring force holds the module in place between the liner and the housing. Each TE module contains 48 thermoelectric couples in an electrical series/parallel ladder arrangement for redundancy. This is extremely effective in minimizing the effect of a single couple failure and improving overall generator reliability. One, or possibly several, couple failures are unlikely to significantly reduce generator power output.

The plutonium dioxide fuel is located within GPHS assemblies in the interior of the generator. The fuel continually produces helium gas as a result of the alpha decay process. Helium gas build-up could potentially stress the MMRTG housing containment (or require an unnecessarily thick and heavy housing) if not released. Also, helium can significantly increase parasitic insulation heat losses through the thermoelectric converter. For these reasons, the MMRTG is separated into two distinct chambers; the heat source and the thermoelectric chambers. The chambers are separated by a thin metal liner. The heat source chamber has a helium vent to the exterior to prevent a gas build up. The thermoelectric section is hermetically sealed with an inert argon cover gas for low heat losses and protection of the thermoelectrics from chemical interactions, such as oxidation. Isolating the TE converter from the heat source chamber allows similar operating power levels in both the vacuum of space and gaseous atmospheres, such as on Mars and Titan. Previous thermoelectric system designs (such as the silicon germanium generator, which used Multi-foil thermal insulation) required a space vacuum environment for longterm operation. These new design features allow the
MMRTG to be stored in normal room environments without active temperature control, electrical control, or gas management. [6]

The RPS Program is working with the DOE to develop an MMRTG "user's guide" that can be used by mission and power systems planners for mission concept development. This users' guide is schedule to be available in 2016 .

\section{7. eMMRTG}

The MMRTG powering the Curiosity rover on Mars was developed by DOE with industrial partners Aerojet Rocketdyne and Teledyne Energy Systems Inc. The MMRTG is performing as predicted. Power output at landing was $\sim 114 \mathrm{~W}$ [7] and has now declined to $\sim 102 \mathrm{~W}$ after $\sim 34$ months on Mars. Over the last two decades, scientists at JPL have developed TE couples using skutterudite (SKD) materials [8] that may allow operation at higher temperatures and offer increased conversion efficiency. In 2012, the RPS Program evaluated this technology and deemed it ready to transfer to an industrial partner for larger-scale production and readiness for potential use in future NASA science mission concepts of several varieties (orbiters, flybys and rovers)..

NASA authorized a set of trade studies to address questions related performance potential, required system modification and costs to flight. Three distinct breakpoints were evaluated in the design for the relative cost-to-benefit ratios and are shown in Figure 3. At Breakpoint 1, the benefit of replacing the MMRTG's PbTe/PbSnTe TE couples with SKD thermoelectric couples was evaluated. At Breakpoint 2, the next natural technology limit when boosting BOM power by at least $15 \mathrm{~W}$ with the new TE couples was to be identified. At Breakpoint 3, the next natural breakpoint was to be identified. Through these evaluations, the degree of required design changes to the generator to achieve the next logical design points can be estimated.

Breakpoint 2 required relatively modest changes to the generator yet boosted power significantly, and was selected as the current reference baseline for the eMMRTG. The reference baseline eMMRTG would produce an estimated $145 \mathrm{~W}$ when compared with the MMRTG's $117 \mathrm{~W}$ nominal output at fueling. Thus, the eMMRTG promises an estimated $25 \%$ gain in output power at fueling. However, due to reduced performance degradation of the new material, the eMMRTG has an estimated $50 \%$ greater power output at the end of design life (17 years). The other two breakpoints either generated too little a power boost or required too much investment for the power gain they would provide. Simply inserting the new TE couples into an MMRTG only increased power to $122 \mathrm{Watts}(\mathrm{W})$; a gain of just $5 \mathrm{~W}$. Going beyond Breakpoint 2 would mean increasing internal temperatures of the MMRTG significantly, while gaining only $11 \mathrm{~W}$. The SKD thermoelectric couple performance over a 17 -year period has not been fully characterized, but it is expected that 
setting hot junction temperatures above $600^{\circ} \mathrm{C}$ would likely accelerate performance degradation and possibly prevent the eMMRTG from performing within specification over a 17year period. Increasing the hot junction temperatures to approximately $650^{\circ} \mathrm{C}$ was deemed unjustifiable for the limited return on power output.

Thus, the key differences between the MMRTG and the baseline eMMRTG, which is depicted in Figure 4, are: 1) the use of the skutterudite TE couples to allow for higher temperature operation which results in higher conversion efficiency; 2) an increase in the average TE couples hot junction temperature from $512^{\circ} \mathrm{C}$ to $600^{\circ} \mathrm{C}$ at beginning of life (BOL) to take advantage of the higher temperature materials; and 3) the addition of a high-emissivity finish on the inner surface of the thermal liner to facilitate the hot junction temperature increase. Only relatively low-risk system modifications appear to be necessary to accommodate the inclusion of the skudderudite TE couples. The current best estimates for projected eMMRTG performance parameters are provided in Table 2.

The evaluation power estimates were made for a Mars "hot case," which assumes a set of boundary conditions that mimic the worst-case thermal environment estimated for the MSL rover on Mars. This practice combines several measureable and distinct environmental parameters (i.e., solar intensity, atmospheric conditions, and ground temperatures) with rover temperatures to form a single temperature to represent heat rejection conditions. The worst-case MSL thermal sink for the MMRTG using this method is estimated at $270 \mathrm{~K}$, which occurs at noon on a hot summer Martian day. The estimated MMRTG fin temperature of the MMRTG under these heat rejection temperatures is $177{ }^{\circ} \mathrm{C}$. The equivalent estimated fin root temperature for eMMRTG is effectively the same, $177^{\circ} \mathrm{C}$.
One of the largest potential benefits the increased efficiency of an eMMRTG would be to enable future missions, such as a Europa or Uranus mission, to be performed using only three or four eMMRTG units instead of the currently projected five MMRTGs. This offers a potential mass savings of $\sim 44$ to $\sim 88$ $\mathrm{kg}$. Also, using one or two fewer RTGs per mission reduces the consumption of the limited U.S. supply of plutonium dioxide fuel. Taken together, the potential benefit of the project is considerable. The SKD Technology Maturation (STM) task is currently transferring skutterudite material and TE couple technology developed at JPL to industry. If this transfer is successful, DOE can work with its industry partners to build eMMRTGs for space exploration. The STM TE couple is shown in Figure 5 along with a MMRTG TE couple. The first generation eMMRTG couples are being manufactured by Teledyne Energy Systems Incorporated (TESI), and tests on a limited set show they meet the power specification of $>206 \mathrm{~mW}$ per couple. TESI is also evaluating insulation options to surround the TE couple legs and the hotand cold-shoes at the higher operating temperatures.

The eMMRTG TE couple development activity is the first exercise of the formal gated technology maturation process now being exercised by NASA and DOE. The review of the first eMMRTG technology maturation gates was conducted in the fall of 2015. The first gate concentrated on evaluating whether the SKD technology was successfully transferred to industry. The assessment by an independent review team in addition to an evaluation by NASA and DOE program executives concluded that the first gate was successfully passed and agreed to continue Phase B of the technology maturation plan. [9]

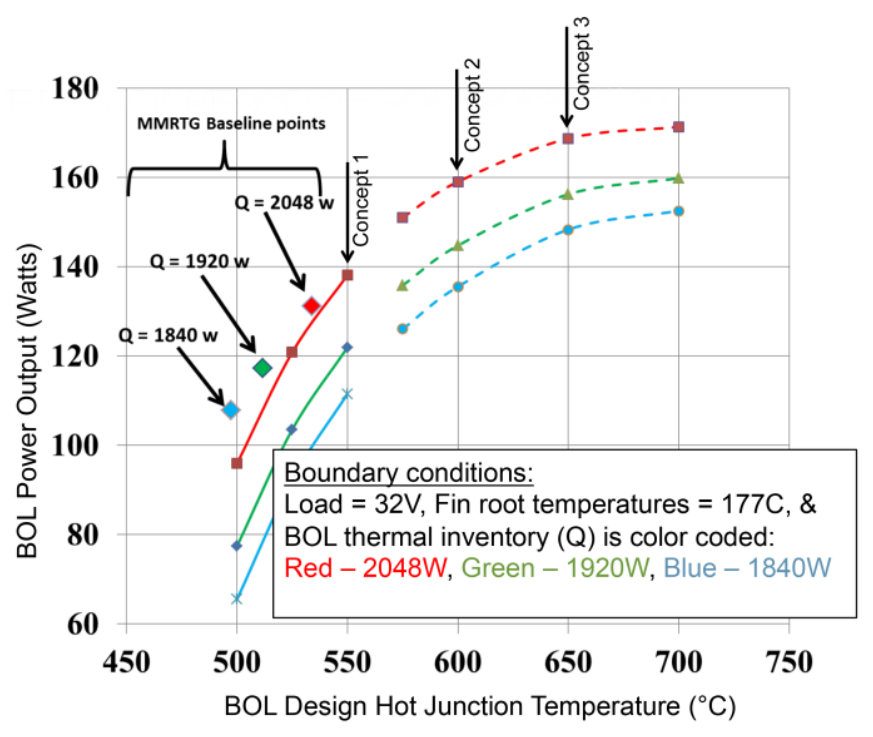

Figure 3. Power Estimate for Concepts 1-3 plotted as functions of hot junction temperature (Thj) and BOL Q. Concept 2 is the enhanced MMRTG. The solid lines are the cases where only the TE couples were replaced in the generator. The dashed lines are for the cases where additional design changes were made to boost power further 


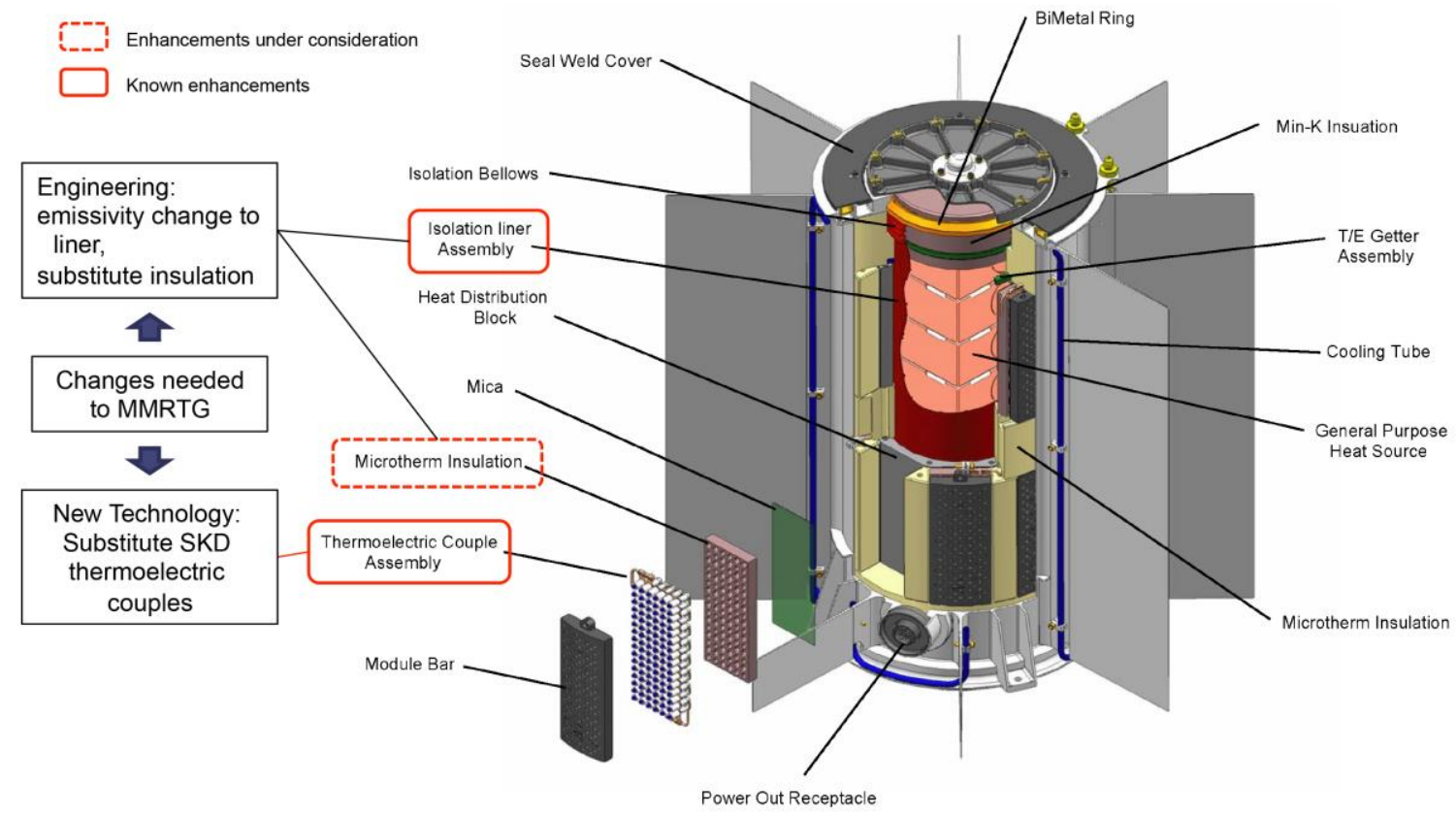

Figure 4. An enhanced MMRTG (eMMRTG) results from changing items in red boxes.

Table 2. Nominal current best estimates of projected eMMRTG performance parameters

\begin{tabular}{|l|l|}
\hline \multicolumn{1}{|c|}{ Parameter } & \multicolumn{1}{c|}{ eMMRTG } \\
\hline Power, electrical $\left(\mathrm{BOM}^{*}\right)$ & 141 \\
\hline Power, thermal $\left(\mathrm{BOM}^{*}\right)$ & $2,000 \mathrm{Wth}$ \\
\hline Design Lifetime & $17 \mathrm{yrs}(14 \mathrm{yrs}$ operational $)$ \\
\hline Diameter, fin-tip to fin-tip & $64 \mathrm{~cm}(25 \mathrm{in})$ \\
\hline Height & $66 \mathrm{~cm}(26 \mathrm{in})$ \\
\hline Mass & $43 \mathrm{~kg}(94 \mathrm{lbs})$ \\
\hline Voltage Range & $23-34 \mathrm{~V} \mathrm{dc}$ \\
\hline Max Fin Root Temperature & $200 \mathrm{C}$ \\
\hline Random Vibration Qual Limit & $0.2 \mathrm{~g} 2 / \mathrm{Hz}$ \\
\hline Pyrotechnic Shock Qual Limit & $6,000 \mathrm{~g}$ \\
\hline
\end{tabular}

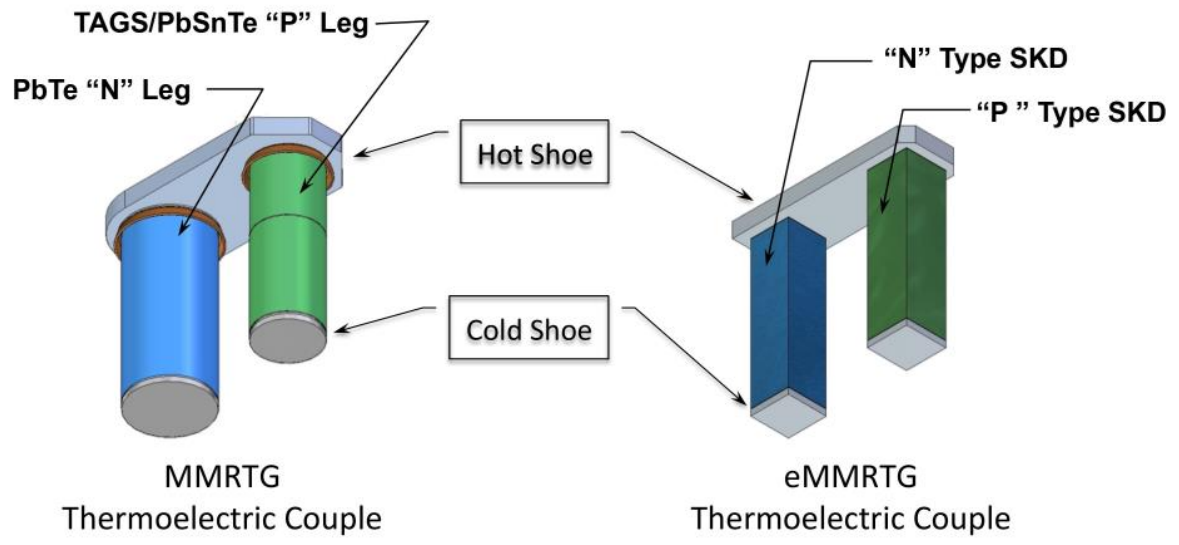

Figure 5. Comparing MMRTG and eMMRTG thermoelectric couples 


\section{SUMMARY}

The goal of NASA's Radioisotope Power Systems (RPS) Program is to make RPS ready and available to support the needs of the planetary science and exploration community. To meet this goal, the RPS Program works closely with the Department of Energy to implement a process by which potential RPS systems and missions are studied and assessed to inform optimal investments by the NASA Science Mission Directorate. This process is being applied today in both thermoelectric and Stirling applications of radioisotope power. This paper described these processes and how they are being used. This paper further described the currently available system, the MMRTG, for which a user's guide will be available in 2015. By integrating new thermoelectric material into this generator, an enhanced MMRTG is possible. This system may afford missions greater than $50 \%$ power at the end of the generator's design life. Not only is this a worthwhile near-term investment for NASA, but by following the processes laid out by the program, this investment should sustain the thermoelectric capabilities necessary to support future missions for decades to come.

\section{REFERENCES}

[1] McNutt, R.L., Ostdiek, P. H., Nuclear Power Assessment Study Final Report, JHU/APL contract report TSSD23122, February 2015, released June 2015.

[2] Hendricks, T. J., Derkevorkian, A., Kolaini, A. R., Keyawa, N. R., Neff, D. J., Nesmith, B. J., Pyroshock Induced Loads Driving Electrical, Thermal, and Structural Impacts in Multi-Mission Radioisotope Thermoelectric Generators (MMRTGs), Proceedings of Nuclear \& Emerging Technologies for Space, (NETS) 2015 Albuquerque, NM, February 23-26, 2015.

[3] Hibbard, K. E., Mason, L. S., Ndu, O., Smith, C., Withrow, J. P., Stirling to Flight, IEEE Aerospace Conference, March 2016.

[4] C.F. Bolden, Jr., National Aeronautics and Space Administration FY2014 President's Budget Request, in: NASA Administration (Ed.), Washington, D.C., 2013, pp. 657.

[5] J. Casani, G. Burdick, R. Carpenter, T. Frazier, D. McPherson, A. Mehner, J. Parrish, L. Rutger, R. Wilcox, Report of the RPS Provisioning Strategy Team, 2001, pp. vii and 124.

[6] Woerner, D. F., Moreno, V., Jones, L., Zimmerman, R., Wood, E., The Mars Science Laboratory (MSL) MMRTG In-Flight: A Power Update, Proceedings of Nuclear and Emerging Technologies for Space 2013, Albuquerque, NM, February 25-28, 2013, Paper 6748

[7] Woerner, D. F., Another update on the Multi-Mission Radioisotope Thermoelectric Generator powering the Curiosity Rover, Journal of Thermoelectricity, No. 1 (2015), 68-78

[8] Woerner, D., Cairns-Gallimore, D. , Zakrejsek, J., O’Mally, T., Getting to an enhanced MMRTG, 2014 Nuclear and Emerging Technologies for Space Conference, NASA Stenniss Space Center, February 2014.

[9] Fountain, G., Ianello, C., Christenbury, T., Maggio, G., Sakamoto, J.,..., Kramer, D., The Final Report of the Standing Review Board for the Skutterudite Technology Maturation Gate 1 Review, November 14, 2015, APL document number TBD. 


\section{BIOGRAPHY}

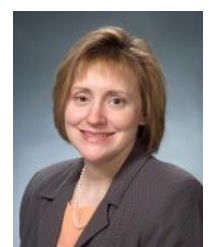

June F. Zakrajsek has over 20 years of aerospace systems development, research and project management experience. She has led internal discipline teams for space systems health management, ISS power systems analysis, and Biotechnology. She has worked as a project manager in the areas of health management, systems engineering and analysis, propulsion system development, Orion Crew Module and Test \& Verification, and Radioisotope Power Systems. Currently June serves as the Program Planning and Assessment Manager for NASA's Radioisotope Power Systems Program. This area is responsible to develop and maintain the implementation strategy for the Program by managing mission and systems analysis functions, integration of new technology into generators, and interfaces with potential missions considering utilizing Radioisotope Power Systems. She holds a Masters in Biomedical Engineering from Case Western Reserve University and Masters and Bachelors in Mechanical Engineering.

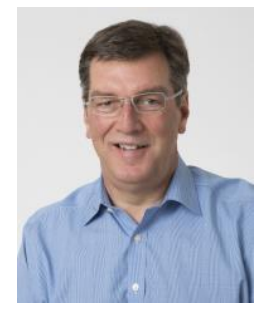

David Woerner has more than 30 years' experience as a systems engineer and manager at JPL including as the MMRTG Office Manager for the Mars Science Laboratory mission. He is presently leading the engineering of an enhanced MMRTG and is the RTG Integration Manager and Deputy Program and Planning Manager for NASA's Radioisotope Power System Program. Woerner has worked at JPL on such missions as Galileo, Cassini, Magellan, Mars Pathfinder, and MSL. He was the Chief Engineer of the avionics for the Mars Pathfinder mission that successfully landed on Mars on July 4, 1996. He is the Chair of the Board of Directors for the IEEE Aerospace Conferences. He has won numerous NASA awards including earning NASA's Exceptional Service and Exceptional Achievement Medals.

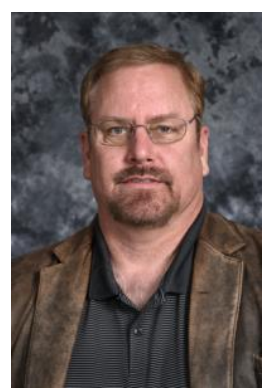

Dr. Stephen Johnson is currently Director of the Space Nuclear Power and Isotope Technologies Division in the Nuclear Science and Technology Directorate of the Idaho National Laboratory. Dr. Johnson oversees the Engineering Development Laboratory and the Space and Security Power Systems Facility and manages the Radioisotope Power Systems Program. He has served as the Director of the Technical Integration Office for DOE's Office of Space and Defense Power Systems since 2012. Most recently this program fueled, tested and delivered the MMRTG for NASA's Mars Scientific Laboratory mission to the planet Mars. During his tenure, the laboratory successfully pursued involvement in the Radioisotope Power Systems Program and following that involvement the fueling and testing of space and terrestrial power systems operations were transferred from Mound Laboratory to the Idaho National Laboratory. Dr. Johnson has over 25 years of experience working with radioactive materials and the analysis of such using either chemical or material science techniques and methods and has extensive knowledge of analytical chemistry spectroscopic methods of analysis and analysis related to characterizing high-level waste for geologic disposal. He holds a B.S. degree with a double major in Mathematics and Chemistry from Lake Superior State University (1984) and a Ph. D. in Physical Chemistry from Iowa State University (1990). 